\title{
A questão da saúde mental e atenção psicossocial: consideraçôes acerca do debate em torno de conceitos e direitos
}

\author{
AMARANTE, Paulo. \\ Saúde mental e atenção psicossocial. \\ Rio de Janeiro: Fiocruz, 2007. \\ | Karoline Vitorino da Silva de Paula | \\ Cientista social, mestre e doutor em Saúde Coletiva. Professor da Universidade de Brasília - UnB. Endereço eletrônico: Graduada em \\ Ciências Sociais. Bolsista PIBIC / UNIOESTE /CNPq. Endereço eletrônico: karol_vit@yahoo.com.br
}

A situação da assistência psiquiátrica no Brasil, restrita ao modelo hospitalocêntrico, foi marcada pela ineficácia dos tratamentos e a violação dos direitos humanos. No final da década de 1970, muitos debates sobre a loucura e os efeitos da instituição asilar vieram à tona, e a questão da violência institucional e da segregação dos internos tornou-se pauta principal das discussóes dos profissionais de saúde e grupos de familiares de internos. $\mathrm{O}$ modelo até então utilizado, com vistas a isolar e internar, mostrava sinais de falência.

Em 1989, um projeto de lei do deputado Paulo Delgado, apresentado ao Congresso Nacional, sugeria um novo modelo de tratamento na assistência psiquiátrica. Este modelo intensificou ainda mais os debates sobre a questão antimanicomial, provocando polêmicas entre diversos setores e grupos sociais. Não virou lei, mas em 2001 um projeto substitutivo configurou-se na Lei Federal $n^{\circ}$ 10.216, que trata essencialmente dos direitos dos portadores de doenças mentais e de uma reorientação do modelo assistencial, redirecionando o atendimento para serviços de base comunitária.

É neste contexto que se situa o livro Saúde mental e atenção psicossocial, de Paulo Amarante. O autor capixaba especializou-se em psiquiatria no Rio de Janeiro e tornou-se um dos pioneiros do movimento brasileiro de reforma psiquiátrica. É Mestre em Medicina Social, Doutor em Saúde Pública e Doutor honoris causa da Universidade Popular das Madres da Plaza de Mayo. Foi presidente nacional do Centro Brasileiro de Estudos de Saúde (Cebes), editor da revista Saúde em Debate e representante eleito do Movimento Nacional da Luta 
Antimanicomial na Comissão Intersetorial de Saúde Mental do Conselho Nacional de Saúde. É coordenador do Grupo de Trabalho em Saúde Mental da Abrasco, membro da Diretoria Nacional do Cebes, professor, pesquisador titular e coordenador do Laboratório de Estudos e Pesquisas em Saúde Mental e Atenção Psicossocial (LAPS) da Escola Nacional de Saúde Pública Sergio Arouca da Fundação Oswaldo Cruz (ENSP/Fiocruz).

Lançado em 2007 pela Editora Fiocruz, o livro Saúde Mental e Atenção Psicossocial instiga o leitor a refletir sobre todo o percurso da assistência psiquiátrica desde as bases da psiquiatria e do manicômio até os projetos atuais de construção de um novo "lugar social" para as pessoas em sofrimento psíquico. O livro faz parte de uma coleção, Temas em Saúde, que busca trazer panoramas sobre conceitos e conteúdos fundamentais nas áreas de saúde.

No primeiro capítulo, "Saúde mental, territórios e fronteiras", partindo do pressuposto de que a saúde mental é uma área muito extensa e complexa do conhecimento, o autor levanta questionamentos sobre a conceituação de saúde mental e também sobre a especificidade do profissional que "trabalha na saúde mental”. Para Amarante, a saúde mental não se restringe apenas à psicopatologia ou à semiologia e não pode ser reduzida ao estudo e tratamento das doenças mentais. Além da psiquiatria, a complexa rede de saberes da temática da saúde mental apresenta a psicologia, a psicanálise, a fisiologia, a filosofia etc.

Diante disto, o autor provoca reflexões sobre a assistência psiquiátrica ao questionar o que é doença mental e se esta seria o oposto de saúde mental. Quais então seriam os limites do campo da saúde mental? Amarante afirma que a natureza do campo contribui para um pensamento em termos de complexidade, simultaneidade, transversalidade de saberes, construcionismo e reflexidade. Logo, a saúde mental é um campo polissêmico e plural na medida em que diz respeito ao estado mental dos sujeitos e das coletividades que são condições altamente complexas.

Em “Uma instituição para loucos, doentes e sãos”, segundo capítulo, Amarante dá prosseguimento à discussão iniciada no capítulo anterior e revisa os primeiros passos da ciência denominada "alienismo", pioneira no estudo do que se conhece como "transtornos mentais". Para tanto, torna-se necessário citar Philippe Pinel, "o pai da psiquiatria”. Amarante explica que Pinel participou ativamente dos acontecimentos da Revolução Francesa, processo que marcou fortemente a humanidade, ao introduzir transformações econômicas, sociais e políticas. 
Uma das mudanças mais relevantes, segundo Amarante, da Revolução Francesa no setor da saúde mental, diz respeito à transformação do hospital em instituição médica. Inicialmente, na Idade Média, o hospital tinha como objetivo dar abrigo, alimentação e assistência religiosa aos pobres, miseráveis etc. Já no século XVII, os hospitais passaram a cumprir uma função de ordem social e política mais explícita. Ao passo que novas instituiçóes assistenciais foram sendo criadas, o hospital assumiu uma nova finalidade: tratar os enfermos. Com o tempo, o alienismo pineliano ganhou o mundo e vários hospitais de alienados foram criados, reproduzindo os princípios e as estratégias estimuladas por Pinel.

Em "Das psiquiatrias reformadas às rupturas com a psiquiatria”, capítulo 3, Amarante destaca algumas críticas quanto às práticas do alienismo e do modelo de ciência positiva que o autorizou e legitimou. Segundo ele, os primeiros asilos criados foram rapidamente superlotados de internos, e a dificuldade em estabelecer os limites entre a loucura e a sanidade era patente. Uma primeira tentativa de recuperar o potencial terapêutico da instituição psiquiátrica deu-se com a proposta das "colônias de alienados". Porém, pouco tempo depois, as colônias mostraram-se iguais aos asilos tradicionais.

Neste contexto, em vários países surgiram as primeiras experiências que buscavam uma "reforma psiquiátrica", mas Amarante se detém na apresentação de apenas algumas, tendo o cuidado de dividi-las em grupos. O primeiro era composto pela Comunidade Terapêutica e pela Psicoterapia Institucional; o segundo grupo, formado pela Psiquiatria de Setor e a Psiquiatria Preventiva; e no terceiro estavam a Antipsiquiatria e a Psiquiatria Democrática, mesmo que estas não sejam, segundo Amarante, experiências de "reformas psiquiátricas" no sentido estrito.

No capítulo 4, "Estratégias e dimensões do campo da saúde mental e atenção psicossocial", o autor retoma algumas características do modelo psiquiátrico. Para Amarante, o modelo psiquiátrico, baseado na hospitalização, pressupõe um paciente portador de um distúrbio que lhe rouba a razão, um insano, insensato, incapaz. $\mathrm{O}$ sistema hospitalar, segundo o autor, em muito se aproxima das instituiçōes carcerárias, correcionais e penitenciárias, pois é um sistema fundado na vigilância, controle e disciplina. Sendo assim, as experiências de reformas psiquiátricas tiveram que superar o desafio de ir além da visão que reduz o processo à mera reestruturação de serviços.

$\mathrm{O}$ autor explica que o processo de reforma psiquiátrica é uma conseqüência natural de uma transformação da própria ciência. Um importante passo neste 
sentido, destacado por Amarante, foi o fato de os serviços terem passado a lidar com as pessoas e não mais com as doenças. Desta forma, rompeu-se com o modelo teórico-conceitual até então vigente e o campo da saúde mental e atenção psicossocial passou por um conjunto de transformações e inovações que contribuíram para a construção de uma nova imagem social dada à loucura e aos sujeitos "em sofrimento". A questão dos direitos humanos também possui importância singular, pois trata da inclusão de novos sujeitos de direito e novos direitos para os sujeitos em sofrimento mental. Nesta perspectiva, a promulgação da Lei Federal no 10.216/01 e a aprovação de demais leis estaduais de reforma psiquiátrica serviram de legitimação, embora a construção da cidadania diga respeito a um processo mais complexo de mudança de mentalidades.

No último capítulo, "Caminhos e tendências das políticas de saúde mental e atenção psicossocial no Brasil”, Amarante faz uma importante referência ao termo "usuário", introduzido pela legislação do SUS em 1990. O autor explica que com este termo se destaca o protagonismo do que anteriormente era apenas um "paciente"; mesmo assim não deixa de ser alvo de muitas críticas pelo fato de ainda manter a relação do sujeito com o sistema de saúde.

Dentre o conjunto de estratégias e princípios no campo da saúde mental e atenção psicossocial no Brasil, o autor destaca: as estratégias de residencialidade e emancipação dos sujeitos; o apoio das cooperativas, centros de convivência e empresas sociais; e também a atenção primária em saúde, que tem como foco a saúde da família e objetiva reverter o quadro centrado apenas na doença e no tratamento.

Ao final do livro, além de fazer sugestôes de leituras e filmes, o autor faz algumas considerações a respeito do novo cenário político de participação e construção no campo da saúde mental e atenção psicossocial. Segundo Amarante, embora sejam muitas as estratégias e dispositivos que vêm contribuir para a configuração de um novo quadro, o hospital psiquiátrico continua a existir. Mesmo "maquiado", ele permanece como "gaiola de ouro", onde não há cidadania, liberdade e autonomia.

Dadas as características da publicação e as propostas iniciais do autor, podemos considerar que em todo o decorrer do livro Amarante se preocupou em conceituar e ampliar o entendimento das estratégias e dimensões do campo da saúde mental e atenção psicossocial. A pequena revisão histórica das bases do alienismo e o processo da reforma psiquiátrica brasileira contribuem para o conhecimento do conjunto de estratégias e princípios no campo da saúde mental, bem como para o 
surgimento de novas discussōes voltadas à assistência. É uma possibilidade, ou oportunidade, de refletir e entender a situação contemporânea da atualmente chamada assistência à saúde mental.

A leitura desse livro pode interessar a todos os estudiosos, profissionais da área e familiares de "usuários" de serviços de saúde mental. Enfim, a todos que pretendam conhecer as questôes deste campo e ter uma visão mais contextualizada sobre as mudanças na área da saúde mental e atenção psicossocial. 